\title{
Short-term variation of autorefraction in Diabetic Macular Edema (DME)*
}

\author{
AY Sukha ${ }^{\alpha}$ and A Rubin ${ }^{\beta}$
}

Optometric Science Research Group, Department of Optometry, APK, University of Johannesburg, PO Box 524, Auckland Park, 2006 South Africa

${ }^{\alpha}<$ baboo@icon.co.za>

$\beta<$ arubin@uj.ac.za>

\begin{abstract}
Very few studies have investigated autorefraction in diabetic subjects presenting either with diabetic retinopathy (DR) and/ or diabetic macular edema (DME). To the best of our knowledge this is the first study using multivariate methods for investigating short-term autorefraction in a small sample of subjects diagnosed with DME. Forty consecutive autorefractor measurements were taken over a short interval on each of seven diabetic subjects with varying stages of DME, and the results were compared to a smaller group of four diabetic control subjects without DME (reasons for the differences in sample sizes will be explained later). Measurements were obtained from both the right and left eyes of all subjects. Subjects in the two groups were similarly matched according to duration of diabetes mellitus (DM), age and glycated hemoglobin (HbAlc) values. Normality of data distribution was mostly achieved with the removal of outliers (where necessary) until profiles of skewness, kurtosis, and standard mean deviation exhibited near-normal distribution. Thereafter, stereo-pair scatter plots with $95 \%$ surfaces of constant probability density (distribution ellipsoids) were generated and compared between the experimental and control subjects.

The diabetic subjects with DME demonstrated a larger spread of measurements in the eyes with the more severe DME, with the exception of one subject (subject 5). The volumes and orientation of the distribution ellipsoids also differed between the subject's eyes. Some eyes with severe DME and poor visual acuity displayed more stigmatic variation (for example, subjects 2 and 4), while others (subjects 1 and 3) displayed more ortho-antistigmatic variation or near oblique antistigmatic variation (subject 7). In all experimental subjects, with the exception of subject 5, the eye with the more severe DME had a larger distribution ellipsoid volume, indicating greater variation in autorefraction and thus it might be surmised that this paper provides some preliminary data to suggest that diabetic subjects with DME display greater short-term variation of refractive behaviour when compared to diabetic subjects without DME. Secondly, in diabetic subjects with DME, eyes with the more severe DME or worse VA also display greater variation of refractive status. However, there seemed to be no distinctive or obvious pattern to the type of variation.

In addition, a suitable statistic in terms of a Cubic Root Difference (CRD) was introduced in this study to compare inter-ocular ellipsoidal volumes. This statistic is also useful for comparing variances between eyes, or between means for groups of eyes, and could be used in studies involving anisometropia, et cetera. Nevertheless, this study suggests that further investigation remains necessary before autorefraction can be used effectively in the early diagnosis, monitoring, and assessment of eyes with diabetic-related complications to the macular regions.
\end{abstract}

${ }^{a}$ BOptom(RAU)

${ }^{\beta}$ DipOptom CAS(NewEnCO) MPhil DPhil(RAU)

* This paper is based on research by the first author for the degree MPhil in the Department of Optometry of the University of Johannesburg with the supervision of Professor Alan Rubin of the Optometric Science Research Group.

Received 2 October 2007; revised version accepted 2 November 2007 


\section{Introduction}

Despite many years of research, diabetic retinopathy (DR) and diabetic macular edema (DME) remain difficult to diagnose, prevent, and treat. There are several reports emphasizing the need for adequate screening of DR and DME, which currently remains a challenge in South Africa ${ }^{1-4}$. Screening for DR and DME is beneficial especially when early detection leads to less vision loss. In South Africa Carmichael et al, have shown 60 degree mydriatic fundus photography to be cost effective and accurate in detecting DR and DME ${ }^{5}$. However, there are reports indicating that the asymptomatic stages of DR and DME are not easily detectable by ophthalmoscopy, fluorescein angiography, or even optical coherence tomography ${ }^{6,}$. This need for early detection is further highlighted by the development of new therapies. Currently the available interventions include laser photocoagulation and vitrectomy that only target more-advanced DR and DME with variable success. Potential pharmacological therapies have recently been developed for targeting the underlying biochemical mechanisms that cause DR and DME. The aim of these therapies is to find the pharmacological agents that can slow down the progression of DR and DME in its early stages ${ }^{6,8}$. With the introduction of these therapies in the future reliable procedures will be needed to detect early DR and DME.

Automated refraction has recently become an accessible, efficient and effective method used to determine refractive status. Very few studies both internationally and locally have investigated refractive status in DM, DR and / or DME using different methods ${ }^{9-11}$. In these studies most researchers have analyzed automated refractive data by either defining refractive status or by using the spherical equivalent refraction (where the prescription is equal to the algebraic sum of the value of the sphere and half the cylinder value) ${ }^{10}$. For example, in The Visual Impairment Project ${ }^{9}$ myopia was defined as a best corrected minus spherical equivalent power greater than $-0.50 \mathrm{D}$. Almost no studies have used multivariate statistics for the analysis of refractive state in DM with the possible exception of one by Rubin et $a l^{11}$. The multivariate approach proves to be more satisfactory for analyzing refractive status. For example, the spread, variation, and distribution of measurements for both spherical and astigmatic components can be studied ${ }^{12-16}$, and therefore this approach has been utilized here. This method has also been utilized in various other studies for comparing dioptric powers and for analyzing variation in refractive status ${ }^{17,18}$.

This study was undertaken to investigate whether the presence of macular disease would affect the shortterm variation or spread of powers in a consistent manner (for example, increasing the magnitude of variation in relation to the severity of DME) that could possibly be used in early diagnosis of DME in individuals with DM. For instance, in the presence of macular disease, ocular fixation stability might be negatively affected and perhaps, greater variation of autorefraction measurements might occur. With more severe DME autorefraction variability might perhaps increase to a more greater extent.

\section{Method}

Seven DME subjects and four control subjects were selected from an original sample of 202 diabetic subjects attending the Diabetic Clinic at the Helen Joseph Hospital in Johannesburg. A Topcon TRC-NW200 non-mydriatic $45^{\circ}$ retinal camera was used to obtain fundus images of both eyes, centered on the macula. This camera allowed for images to be obtained through pupils as small as $3.7 \mathrm{~mm}$ and pupil dilation was encouraged by allowing each subject to spend five minutes in a dark room, and thus, no pharmacological agents were used to dilate the pupils. Image quality was monitored with periodic feedback to the photographers and if necessary more than one photograph was taken. The images were transferred directly to a notebook computer and viewed using software programs such as Adobe Photoshop and Microsoft Photo Editor. The digital images were then evaluated by two experienced ophthalmologists and diagnosed in accordance with the International Clinical Disease Severity Scale ${ }^{19}$.

The Nidek ARK 700 autorefractor was used to record all non-cycloplegic autorefraction measurements. The instrument was adjusted to round measurements to $0.01 \mathrm{D}$ and the vertex distance was set at $0 \mathrm{~mm}$. The stimulus target used in this instrument consisted of a hot air balloon. On all subjects forty measurements per eye were taken and each measurement was printed individually before the next measurement was obtained. The 
decision to obtain the measurements first on the right or left eye was made randomly by using a toss of a coin. All the subjects were instructed to observe the center of the target and no further instructions were given regarding blinking, clearing or keeping the target single. This was done to ensure that the measurements were obtained with the eyes in as a natural state as possible. Thereafter, an optometrist administered a complete subjective refraction on all subjects. Subject identity, diabetes status and all other clinical and medical factors were masked to the ophthalmologists, photographers and optometrists. Forty measurements were also taken on an artificial eye at the beginning, middle, and end of the entire procedure to examine the overall consistency and variability of the measurements taken from this autorefractor.

Table 1.Clinical means, subjective refraction, acuities and profiles of subjects with DME (represented by S), and control subjects (represented by C). LP denotes light perception. Diagnosis of the severity of DME that was made on each eye by the ophthalmologists are indicated next to each eye.

\begin{tabular}{|c|c|c|c|c|}
\hline Type of DME & Clinical Means & Subjective Refraction & Pinhole VA & Subject Profile \\
\hline $\begin{array}{l}\text { S1 } \\
\text { R: Severe } \\
\text { L: Moderate }\end{array}$ & $\begin{array}{c}-0.23 /-0.30 \times 89 \\
0.39 /-0.79 \times 73\end{array}$ & $\begin{array}{l}-0.25 /-0.25 \times 70 \\
0.25 /-0.50 \times 70\end{array}$ & $\begin{array}{l}6 / 7.5 \\
6 / 7.5\end{array}$ & $\begin{array}{l}\text { Age: } 39 \text { yrs } \\
\text { Race: Black male } \\
\text { Type of DM: One } \\
\text { Duration of DM: } 16 \text { yrs }\end{array}$ \\
\hline $\begin{array}{l}\text { S2 } \\
\text { R: Mild } \\
\text { L: Severe }\end{array}$ & $\begin{array}{l}-0.50 /-0.62 \times 57 \\
-0.90 /-0.21 \times 107\end{array}$ & $\begin{array}{l}-0.25 /-0.50 \times 60 \\
-0.50 /-0.50 \times 92\end{array}$ & $\begin{array}{l}6 / 7.5-1 \\
6 / 12+2\end{array}$ & $\begin{array}{l}\text { Age: } 57 \\
\text { Race: White male } \\
\text { Type of DM: One } \\
\text { Duration of DM: } 14 \text { yrs }\end{array}$ \\
\hline $\begin{array}{l}\text { S3 } \\
\text { R: Severe } \\
\text { L: Moderate }\end{array}$ & $\begin{array}{l}0.77 /-0.11 \times 98 \\
0.99 /-0.70 \times 78\end{array}$ & $\begin{array}{l}+0.75 \\
+1.25 /-0.50 \times 54\end{array}$ & $\begin{array}{l}6 / 15 \\
6 / 9-2\end{array}$ & $\begin{array}{l}\text { Age: } 57 \text { yrs. } \\
\text { Race: Coloured female } \\
\text { Type of DM: Two } \\
\text { Duration of DM: } 13 \text { yrs. }\end{array}$ \\
\hline $\begin{array}{l}\text { S4 } \\
\text { R: Severe } \\
\text { L: Severe }\end{array}$ & $\begin{array}{l}0.19 /-0.27 \times 124 \\
-0.13 /-0.59 \times 164\end{array}$ & $\begin{array}{l}-0.50 \times 10 \\
0.0\end{array}$ & $\begin{array}{l}6 / 10 \\
6 / 19+1\end{array}$ & $\begin{array}{l}\text { Age: } 58 \text { yrs. } \\
\text { Race: White female } \\
\text { Type of DM: One } \\
\text { Duration of DM: } 20 \text { yrs }\end{array}$ \\
\hline $\begin{array}{l}\text { S5 } \\
\text { R: Mild } \\
\text { L: Severe }\end{array}$ & $\begin{array}{l}-3.53 /-0.75 \times 175 \\
-5.90 /-0.13 \times 176\end{array}$ & 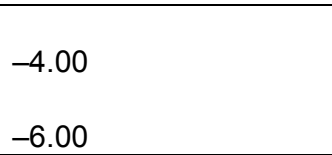 & $\begin{array}{l}6 / 7.5-2 \\
6 / 20-2\end{array}$ & $\begin{array}{l}\text { Age: } 51 \text { yrs } \\
\text { Race: White female } \\
\text { Type of DM: Two } \\
\text { Duration of DM: } 12 \text { yrs }\end{array}$ \\
\hline $\begin{array}{l}\text { S6 } \\
\text { R: Severe } \\
\text { L: Severe }\end{array}$ & $\begin{array}{c}-0.05 /-1.12 \times 107 \\
0.13 /-0.12 \times 67 \\
\end{array}$ & $\begin{array}{l}-0.25 \\
+0.25 /-0.25 \times 60 \\
\end{array}$ & $\begin{array}{l}6 / 30 \\
6 / 6 \\
\end{array}$ & $\begin{array}{l}\text { Age: } 51 \text { yrs. } \\
\text { Race: White female } \\
\text { Type of DM: Two } \\
\text { Duration of DM: } 8 \text { yrs }\end{array}$ \\
\hline $\begin{array}{l}\text { S7 } \\
\text { R: Severe } \\
\text { L: Severe }\end{array}$ & $\begin{array}{r}-1.57 /-1.26 \times 104 \\
0.13 /-1.78 \times 78\end{array}$ & $\begin{array}{l}-1.25 /-1.00 \times 106 \\
0.0\end{array}$ & $\begin{array}{l}6 / 24 \\
\text { LP }\end{array}$ & $\begin{array}{l}\text { Age: } 69 \text { yrs. } \\
\text { Race: Coloured male } \\
\text { Type of DM: Two } \\
\text { Duration of DM: } 18 \text { yrs }\end{array}$ \\
\hline $\begin{array}{l}\mathrm{R} \\
\mathrm{L}\end{array}$ & $\begin{array}{c}-0.58 /-0.35 \times 31 \\
0.02 /-0.37 \times 47\end{array}$ & $\begin{array}{l}-0.25 \\
-0.25\end{array}$ & $\begin{array}{l}6 / 6-1 \\
6 / 6\end{array}$ & $\begin{array}{l}\text { Age: } 60 \text { yrs } \\
\text { Race: Coloured female } \\
\text { Type of DM: Two } \\
\text { Duration of DM: } 10 \text { yrs }\end{array}$ \\
\hline $\begin{array}{l}\mathrm{R} \\
\mathrm{L}\end{array}$ & $\begin{array}{l}-0.81 /-0.63 \times 51 \\
-0.82 /-0.26 \times 107\end{array}$ & $\begin{array}{l}-0.25 /-0.50 \times 17 \\
-0.50 /-0.50 \times 80\end{array}$ & $\begin{array}{l}6 / 3 \\
6 / 3-1\end{array}$ & $\begin{array}{l}\text { Age: } 42 \text { yrs } \\
\text { Race: Coloured male } \\
\text { Type of DM: One } \\
\text { Duration of DM: } 7 \text { yrs }\end{array}$ \\
\hline $\begin{array}{l}\mathrm{R} \\
\mathrm{L}\end{array}$ & $\begin{array}{c}-0.75 /-0.23 \times 0 \\
-0.57 /-0.34 \times 160\end{array}$ & $\begin{array}{l}-0.75 /-0.25 \times 30 \\
-0.75 /-0.25 \times 30\end{array}$ & $\begin{array}{l}6 / 6-2 \\
6 / 6-2\end{array}$ & $\begin{array}{l}\text { Age: } 43 \text { yrs } \\
\text { Race: Black female } \\
\text { Type of DM: One } \\
\text { Duration of DM: } 10 \text { yrs }\end{array}$ \\
\hline $\begin{array}{l}R \\
L\end{array}$ & $\begin{array}{l}-1.71 /-0.27 \times 110 \\
-1.34 /-0.46 \times 27\end{array}$ & $\begin{array}{l}-1.25 /-0.50 \times 94 \\
-1.25\end{array}$ & $\begin{array}{l}6 / 6+2 \\
6 / 3-2\end{array}$ & $\begin{array}{l}\text { Age: } 40 \text { yrs. } \\
\text { Race: Black male } \\
\text { Type of DM: One } \\
\text { Duration of DM: } 10 \text { yrs }\end{array}$ \\
\hline
\end{tabular}




\section{Results}

The scatter plots for the samples measured on the artificial eye at the beginning, middle and end of the time period are not given here as the measurements clustered tightly around the origin and the means on all three occasions were comparable and variation was almost negligible ${ }^{20}$. This indicated that this particular autorefractor was, in general, very consistent while measuring the instantaneous refractive status of the artificial eye.

Clinical means, subjective refraction, pinhole visual acuities, diagnosis of the severity of DME and profiles of subjects with DME and control subjects are tabulated in Table 1. Fundus photographs of subjects with DME are presented in Figure 1. All control subjects were diagnosed with no apparent DR or DME. It should be noted that analyses and results quoted were done under the assumption of multivariate normality. The issues of identification of departures of normality and outliers are complicated and there are several different methods to test for normality, for example, the Shapiro Wilks' $W$ test. However, in this study normality of data distribution was achieved in the following manner. Raw data, stereo-pair scatter plots, and graphs of Mahalanobis distances were used to identify all possible outliers. Polar profiles of skewness and kurtosis were then generated to view normality of the data distribution. Outliers were removed in a stepwise fashion until polar profiles exhibited near normal distribution. For all samples not more than four measurements were removed per sample.

Right Eyes

\section{Subject 1}

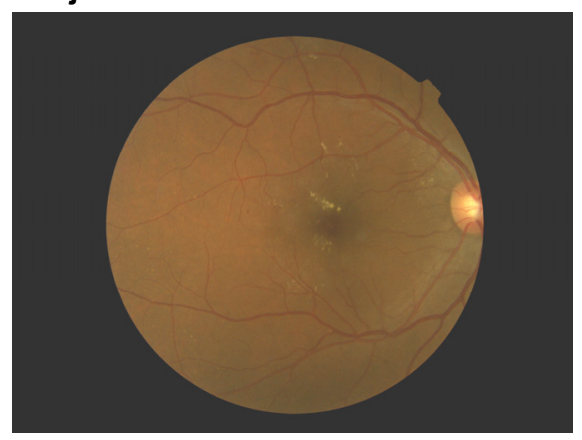

Severe DME, Pinhole VA: 6/7.5

\section{Subject 2}

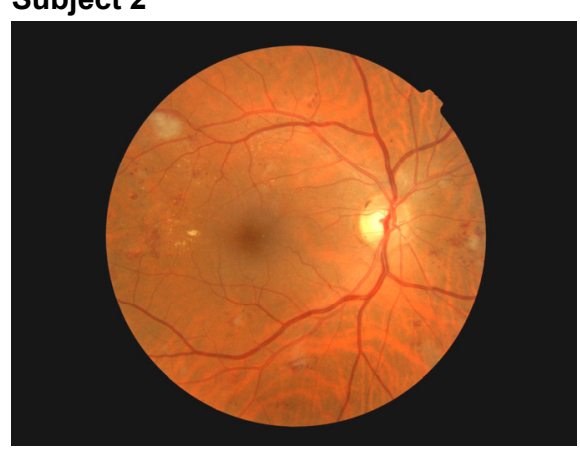

Mild DME, Pinhole VA: 6/7.5-1

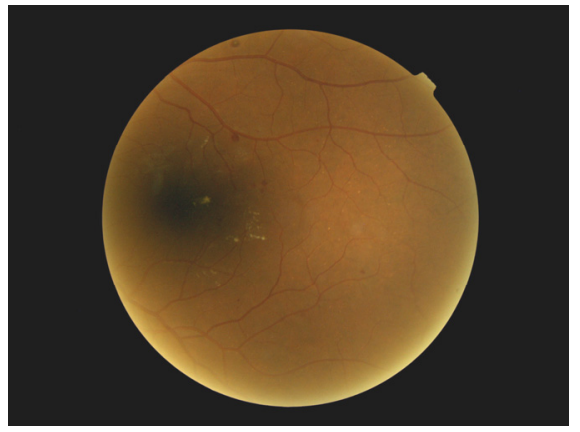

Moderate DME, Pinhole VA: 6/7.5

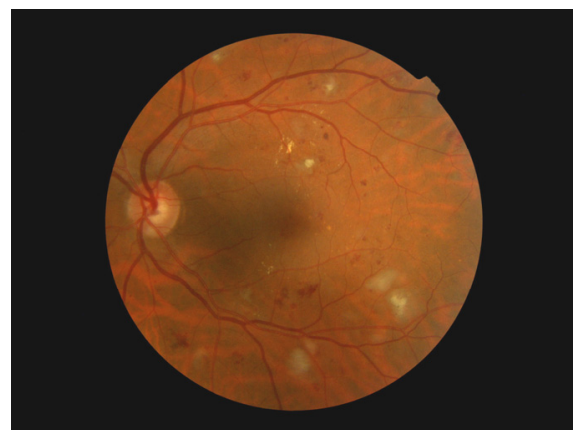

Severe DME, Pinhole VA: 6/12+2 


\section{Subject 3}

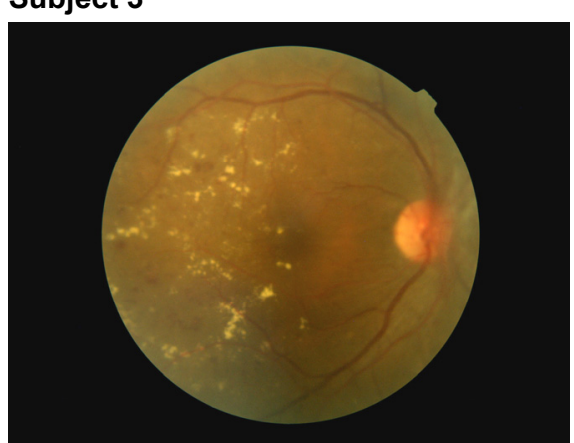

Severe DME, Pinhole VA: 6/15

\section{Subject 4.}

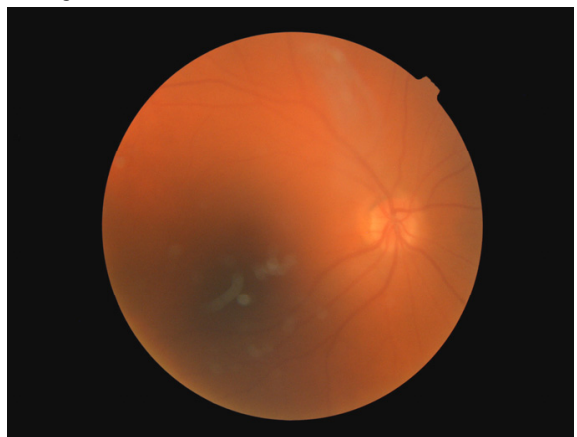

Severe DME, Pinhole VA: 6/10

\section{Subject 5}

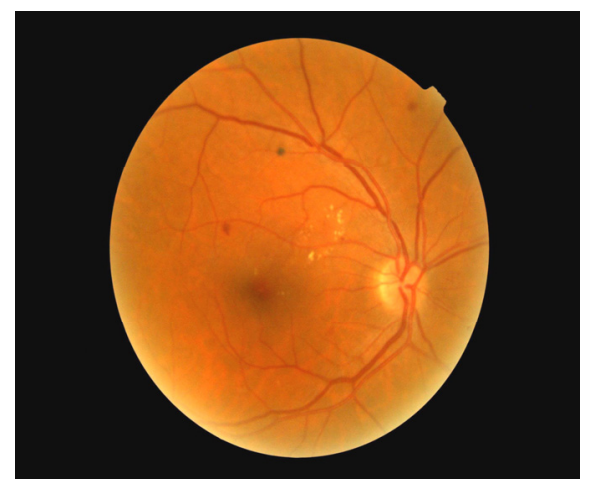

Mild DME, Pinhole VA: 6/7.5-2

\section{Subject 6}

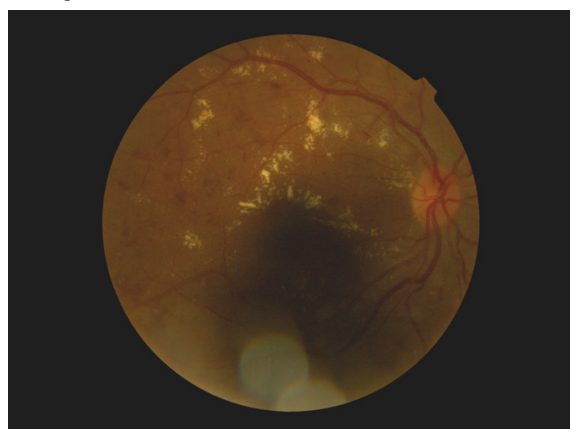

Severe DME, Pinhole VA: 6/30

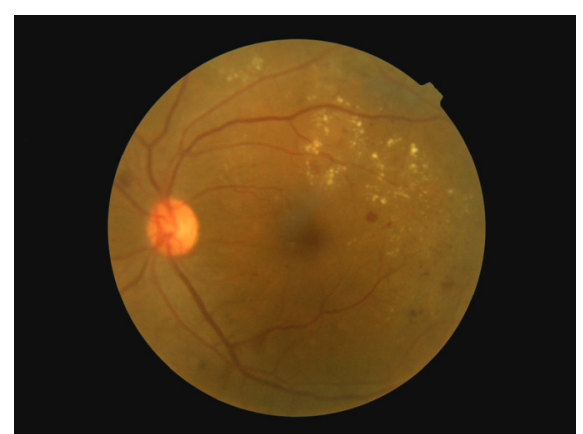

Moderate DME, Pinhole VA: 6/9-2

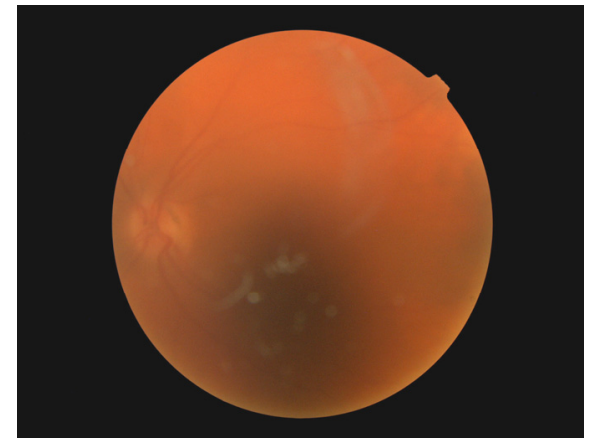

Severe DME, Pinhole VA: 6/19+1

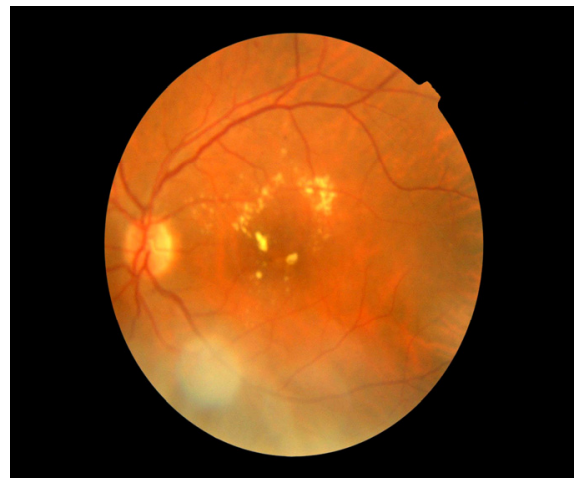

Severe DME, Pinhole VA: 6/20-2

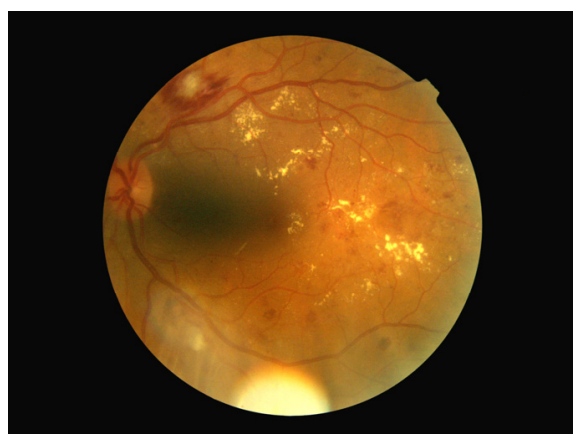

Severe DME, Pinhole VA: 6/6 


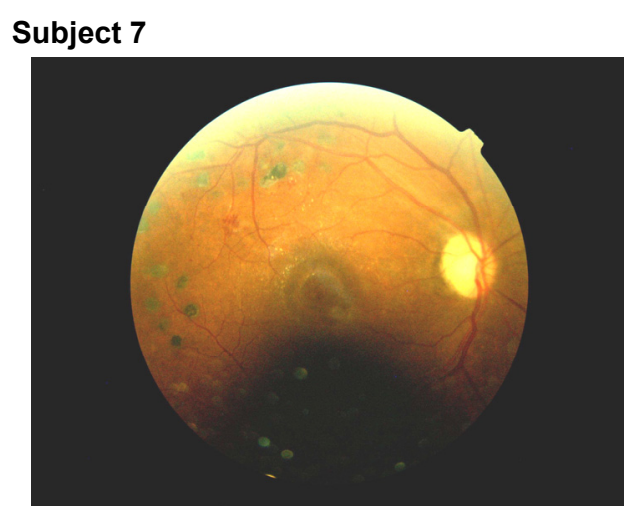

Severe DME, Pinhole VA: 6/24

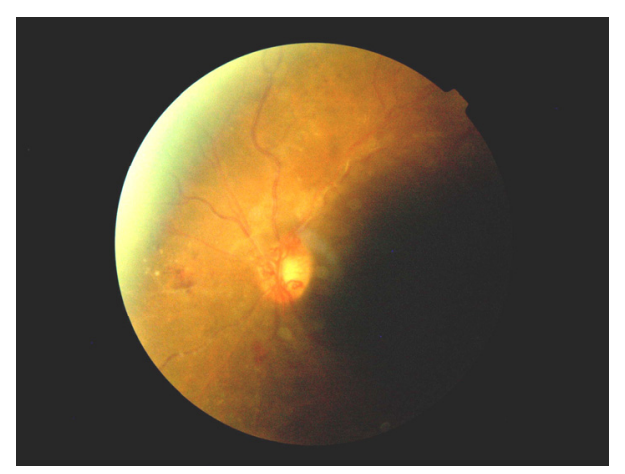

Severe DME, Pinhole VA: LP

Figure 1.Non-mydriatic fundus photographs of DME subjects. Severity of DME as diagnosed by two ophthalmologists and corresponding pinhole visual acuities are provided.

\section{Stereo-pair scatter plots with 95\% surfaces of constant probability density (distribution ellipsoids)}

Figures 2 and 3 illustrate stereo-pair scatter plots with 95\% distribution ellipsoids in the DME and in control subjects respectively. For ease on comparison all plots have an axis length of $2 \mathrm{D}$ and tick intervals of $1 \mathrm{D}$. The origin indicates the sample mean of each eye concerned (see Table 1). Red ellipsoids represent the eye with the more severe DME. From Figure 2 it can be seen for subject 1 that the majority of the points cluster about the origin for both the right and left eyes. The data also seems to vary mainly along the ortho-antistigmatic axis in the right eye, and along the stigmatic axis in the left eye. This can also be seen from the elongated shape of the ellipsoids, which seems to be parallel to the corresponding axes. The slightly larger distribution ellipsoid in the subject's right eye $\left(0.08 \mathrm{D}^{3}\right)$ with the more severe DME indicated a slightly greater variation of measurements, compared to the left eye $\left(0.04 \mathrm{D}^{3}\right)$. However, the difference seems small, and therefore the difference in intraocular variation is possibly not regarded as greatly significant. A point to note is that although the ophthalmologic diagnosis was that the right eye had more severe DME, from Table 1 the pinhole VA in each eye was the same. In subject 2 , the measurements are loosely clustered about the origin of the scatter plots, spreading roughly along the stigmatic axes in both eyes. The left eye with the more severe DME and poorer pinhole VA displayed a greater spread and had larger ellipsoid volume $\left(1.70 \mathrm{D}^{3}\right)$ compared to the right eye $\left(0.94 \mathrm{D}^{3}\right)$. The difference here is thus more pronounced than for subject 1 . Subject 3 also displayed differences in the clustering of measurements with a tighter spread for the left rather than right eye. In the right eye the distribution ellipsoid extended along the $\mathbf{J}$ axis and had, a larger volume $\left(0.14 \mathrm{D}^{3}\right)$ compared to the left eye $\left(0.08 \mathrm{D}^{3}\right)$. Comparison between the scatter plots and distribution ellipsoids for subject 4 revealed for the right eye (with less severe DME and better pinhole VA) that the measurements are more tightly clustered than for the left eye. The volume of the ellipsoids $\left(0.31 \mathrm{D}^{3}\right.$ versus $\left.2.24 \mathrm{D}^{3}\right)$ also indicated much greater variation of measurements in the subject's left eye with the more severe DME. Thus, subjects 1 to 4 all displayed greater short-term variation of autorefraction in the eye classified with more severe DME. However, scatter plots generated for subject 5 displayed contrasting results. The spread of data in the right eye varied loosely mainly along a direction roughly near the ortho-antistigmatic axis and near the I-J plane. In the left eye the data was clustered tightly and the ellipsoid was elongated parallel to the stigmatic axis. The volumes of the distribution ellipsoids were also notably different. The left eye that had been diagnosed with severe DME and poorer pinhole VA, had a smaller volume $\left(0.08 \mathrm{D}^{3}\right)$ indicating less variation, compared to the eye with mild DME and better pinhole VA (with volume $2.03 \mathrm{D}^{3}$ ). Subject 6 who had been diagnosed with severe DME in the right eye and mild DME in the left eye demonstrated greater variation in autorefraction mainly along the orthoantistigmatic axis $\left(F_{\text {or }} \mathbf{J}\right)$ in the right eye. Here a greater ellipsoid volume was found for the right eye $\left(1.47 \mathrm{D}^{3}\right)$ with more severe DME compared to the left eye $\left(0.37 \mathrm{D}^{3}\right)$. Of all these subjects, subject 7 was diagnosed with the most severe DME and displayed the worst VA in both eyes namely 6/24 in the right eye and light perception only in the left eye. Although the subject had light perception in the left eye fixation on the illuminated target 
was possible and autorefraction could be done.A greater spread of measurements was found for the left eye. However, in the right eye the cluster of measurements and ellipsoid extend slightly along the ortho-antistigmatic axis. Again, the volume for the $95 \%$ distribution ellipsoid in the left eye $\left(3.77 \mathrm{D}^{3}\right)$ with the more severe DME and poorer VA was much larger compared to the right eye $\left(1.22 \mathrm{D}^{3}\right)$. Hence, the orientation and volumes of the ellipsoids indicated significant differences between the two eyes.

Control subjects with DM but without DME were included in this study in order to determine to what extent the volumes of $95 \%$ distribution ellipsoids would vary in the absence of macular injury or involvement, and to form a comparison between statistics (for example, cubic root differences) with the experimental group. Only four control subjects were used as against the seven experimental subjects as these results were regarded as being somewhat preliminary in nature. Scatter plots with 95\% distribution ellipsoids for the four control subjects are seen in Figure 3. Measurements for control 1 vary greatly along the stigmatic axis in the right eye and clustered about the origin or mean autorefraction in the left eye. Ellipsoidal volume is greater in the right eye $\left(2.01 \mathrm{D}^{3}\right)$ as compared to the left eye $\left(0.34 \mathrm{D}^{3}\right)$. This subject clearly demonstrates that quite profound differences in short-term variation of autorefraction and volumes of ellipsoids can be found in the absence of factors such as DME (and since the subject was 60 years of age accommodation is unlikely to really be the issue here). Variations in autorefraction in right and left eyes of control 2 are comparable as both eyes show tightly clustered data about their respective means. The right eye measurements extending slightly along the orthoantistigmatic axis and the left eye measurements extending slightly along the stigmatic axis. The 95\% distribution ellipsoid volumes are also comparable for both eyes $\left(0.08 \mathrm{D}^{3}\right.$ and $0.05 \mathrm{D}^{3}$ for right and left eyes respectively). Scatter plots of autorefraction for the right and left eyes of control 3 show that in both eyes data extends along the ortho-antistigmatic axis. However, the left eye showed greater variation as indicated by the volume of the ellipsoid being $0.14 \mathrm{D}^{3}$ as against $0.04 \mathrm{D}^{3}$ for the right eye. Both eyes of control 4 displayed comparable results with each other with slight variation occurring along the ortho-antistigmatic axis in the left eye. The volumes of the two ellipsoids suggested no significant differences in variation of measurements.

\section{Comparison of distribution ellipsoids}

In order to directly compare the volumes of distribution ellipsoids suitable statistics in terms of Cubic Root Differences (CRD) were used in this study. The cubic root difference is defined as:

$$
\text { Cubic Root Difference }=\sqrt[3]{\text { Volume } \max \left(V_{\max }\right)-\text { Volume } \min \left(V_{\min }\right)}=\sqrt[3]{V_{\max }-V_{\min }}
$$

The bigger the cubic root differences the greater the difference in volumes between the eyes. However, two ellipsoids with equal volumes can also be different in terms of orientation. Table 2 represents the cubic root differences of the $95 \%$ distribution ellipsoids for subjects with DME and for the control subjects. From the table it can be seen that subject 7 with the most severe DME demonstrates the largest difference in inter-ocular volumes $(\mathrm{CRD}=1.40 \mathrm{D})$. Furthermore, subjects 4 and $5(\mathrm{CRD}=1.25 \mathrm{D})$ and subject $7(\mathrm{CRD}=1.40 \mathrm{D})$ also display larger differences between the less and more affected eye when compared to the control subjects. The mean cubic root difference for DME subjects was $0.94 \mathrm{D}$ and for control subjects $0.60 \mathrm{D}$ indicating that overall subjects with DME displayed larger differences in ellipsoidal volumes compared to subjects without DME. These statistics can also be used to compare the variances between right eyes and left eyes. 
AY Sukha and A Rubin

Right Eyes

Subject 1
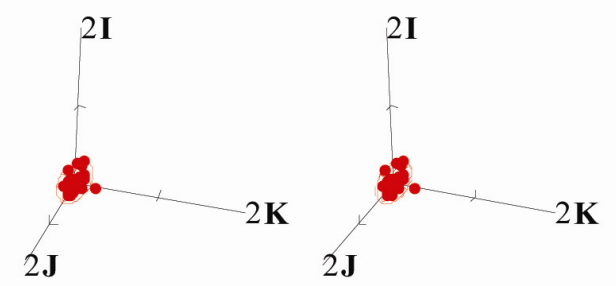

Subject 2
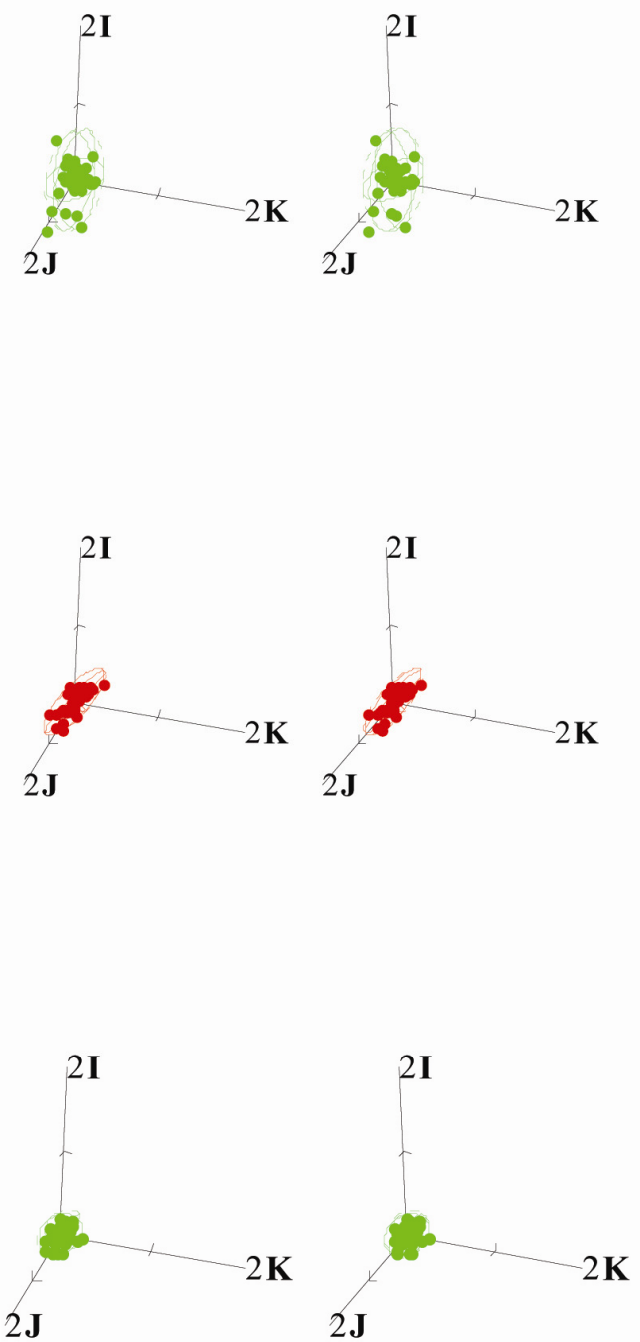

Left Eyes
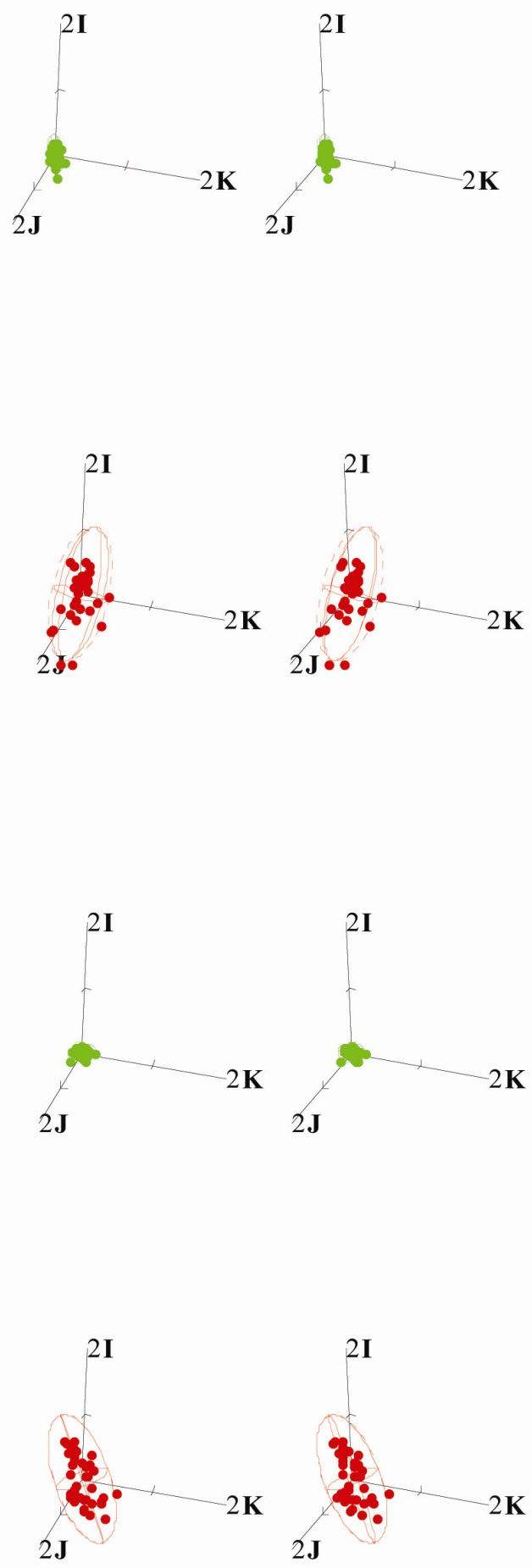


\section{Subject 5}
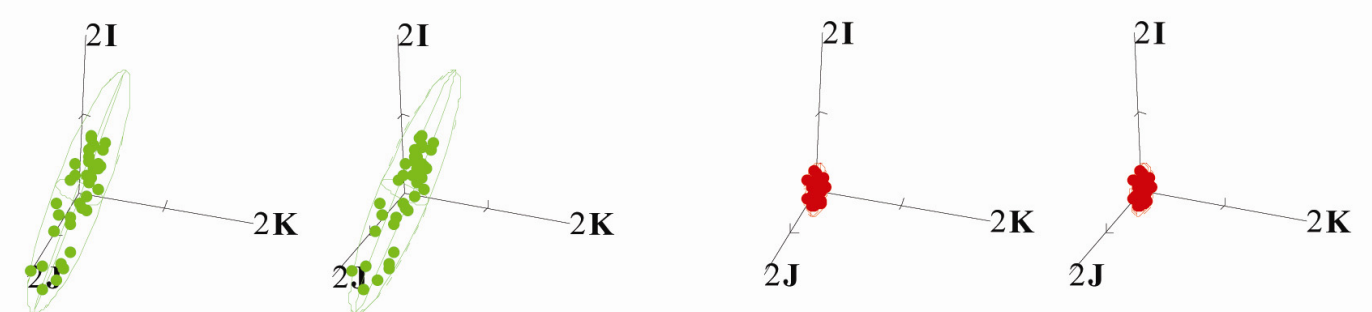

Subject 6
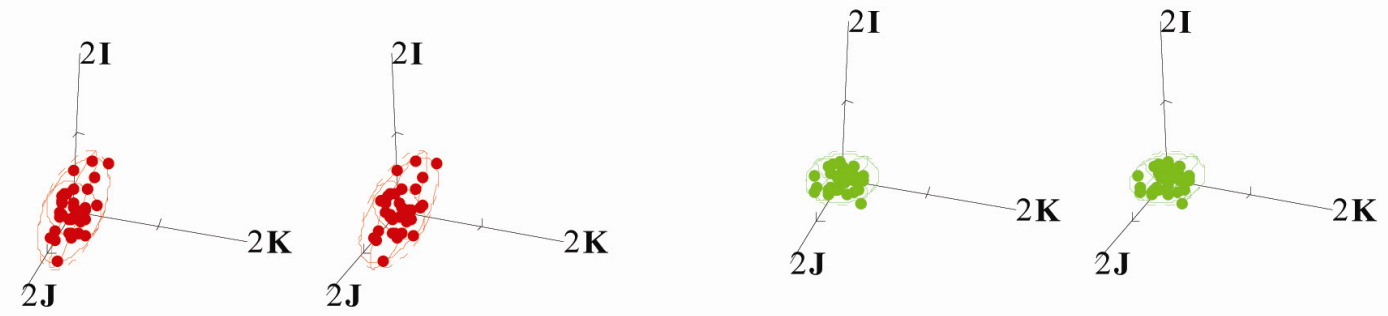

\section{Subject 7}
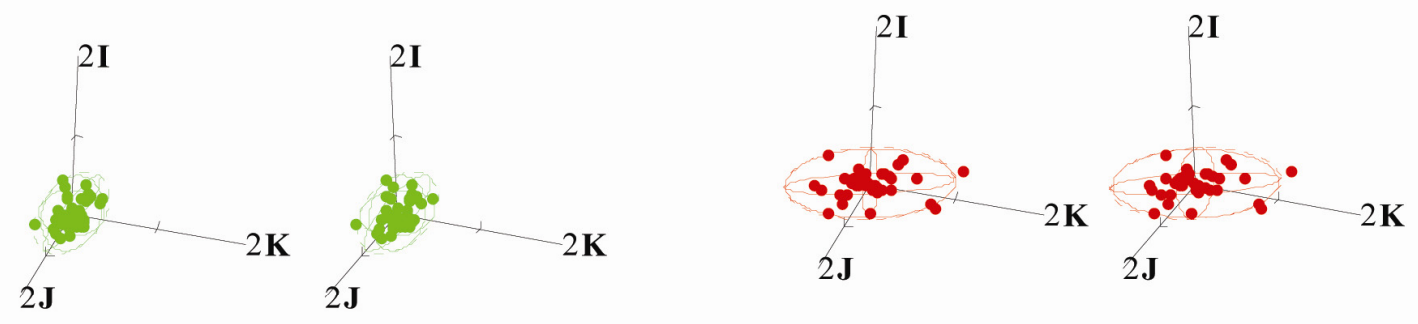

Figure 2. Stereo-pair scatter plots with 95\% distribution ellipsoids for subjects with DME. Red ellipsoids represent the eye with the more severe DME and worse VA. Origins of the stereo-pairs are sample means. For easy comparison tick intervals are $1 \mathrm{D}$, and axes have length $2 \mathrm{D}$. Each dot represents one autorefraction measurement and sample sizes are all greater than or equal to 36 . 
Right Eyes

\section{Subject 1}
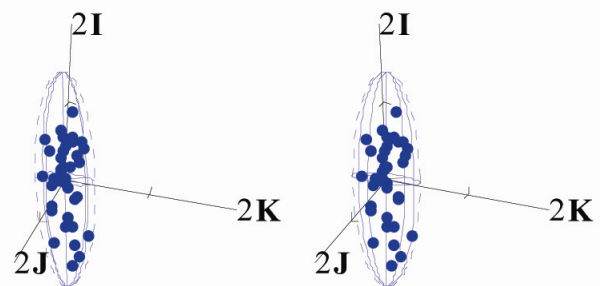

Subject 2
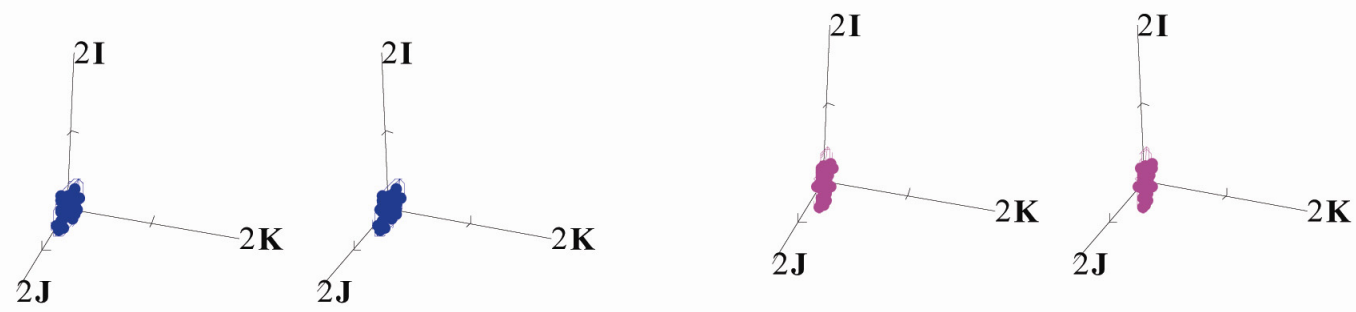

Subject 3
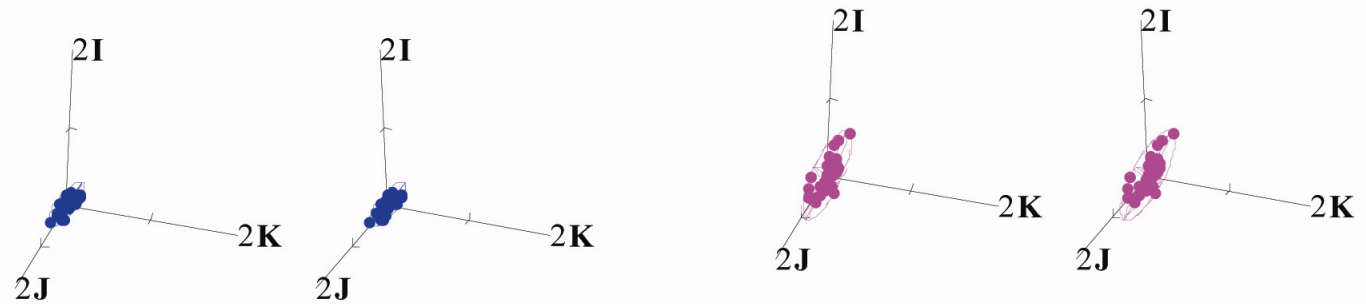

Subject 4
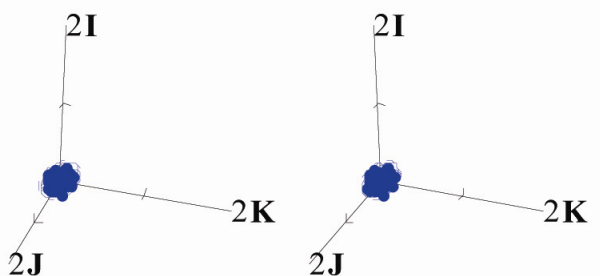

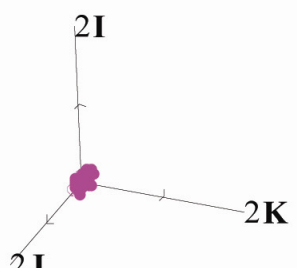

$2 \mathbf{J}$

Figure 3. Stereo-pair scatter plots with $95 \%$ distribution ellipsoids for samples of autorefraction on four control subjects with DM but without DME. Origins are sample means and tick intervals are $1 \mathrm{D}$. The stereo-pairs can be directly compared with those in Figure 2 for the subjects with DM and DME. 
Table 2.The Cubic Root Differences (CRD) of distribution ellipsoids for right and left eyes of subjects with and without (control subjects) DME. The bigger the CRD, the greater the difference in volumes between the eyes. Units are $\mathrm{m}^{-1}$ or $\mathrm{D}$ whereas volumes have units $D^{3}$. The mean CRD for DME subjects was 0.94 and for control subjects 0.60 indicating that overall subjects with DME displayed larger ellipsoidal volumes compared to subjects without DME.

\begin{tabular}{|l|l|l|l|}
\hline \multirow{2}{*}{ Subjects with DME } & \multicolumn{2}{|l|}{ Ellipsoid Volumes $\left.\mathbf{( D}^{3}\right)$} & \multirow{2}{*}{ (CRD) $=\sqrt[3]{V_{\max }-V_{\min }}$} \\
\cline { 2 - 3 } & OD & OS & \\
\hline Subject 1 & 0.078 & 0.038 & 0.34 \\
\hline Subject 2 & 0.94 & 1.7 & 0.91 \\
\hline Subject 3 & 0.14 & 0.08 & 0.40 \\
\hline Subject 4 & 0.31 & 2.24 & 1.25 \\
\hline Subject 5 & 2.03 & 0.08 & 1.25 \\
\hline Subject 6 & 1.47 & 0.37 & 1.00 \\
\hline Subject 7 & 1.22 & 3.77 & 1.40 \\
\hline Control 1 & 2.01 & 0.34 & 1.20 \\
\hline Control 2 & 0.08 & 0.05 & 0.31 \\
\hline Control 3 & 0.04 & 0.14 & 0.46 \\
\hline Control 4 & 0.11 & 0.03 & 0.43 \\
\hline
\end{tabular}

\section{Hypothesis Tests}

Hypothesis tests were performed for both the control subjects (no DME) and subjects with DME. The null hypothesis for equality of variances was rejected at a $95 \%$ level, where $u$ exceeded the $\chi^{2}$ critical values of 12.592. These tests indicated in each, and all, subjects with DME and also for controls that the variances and covariances were significantly different in their right and left eyes. An important point to note is that provided large enough samples are measured per eye, these hypothesis tests on variances and covariances can be sensitive to even very small differences. Nevertheless, these statistically significant differences might not be very meaningful from a clinical or a practical viewpoint. Thus, a difference between two samples of, for example, $0.04 \mathrm{D}^{2}$ might be statistically significant, but clinically it may not be very profound.

\section{Conclusion}

The aim of this study was to compare short-term variation of autorefraction in eyes with different levels of DME, in order to establish whether the refractive behaviour would be different, and whether autorefraction could be used as a means of identifying or diagnosing early DME. Results indicate that overall obvious differences in scatter plots (raw data variation) are observed between Figures 2 and 3, demonstrating greater autorefraction variation in subjects with DME when compared to subjects without DME. Secondly, in six out of seven experimental subjects, greater variation in autorefraction and larger volumes for $95 \%$ surfaces of constant probability density were found for the eye with more severe DME and worse VA with subject 5 as an exception. However, there seems to be no distinct pattern in the type of variation, for example, say towards more stigmatic (that is, towards greater myopia or hyperopia) variance in relation to severity of DME.

Studies reporting on long-term refractive behaviour in DM, DR and/or DME include the Beaver Dam Eye Study ${ }^{10}$; the Visual Impairment Project in Australia ${ }^{9}$; and a study by Espiritu and $\mathrm{Sy}^{21}$. In the Beaver Dam Eye Study the 10-year change in spherical equivalent refraction was determined in 2937 subjects. They concluded that the presence of DM tended to cause a larger shift in hyperopia ${ }^{10}$. The Visual Impairment Project was a population based study that recruited 4744 subjects over the age of 40 years. DR was prevalent in $29.1 \%$ and 
myopia was not reported to be significantly correlated with $\mathrm{DR}^{9}$. Similarly, Espiritu and Sy found no significant association between DME and myopia in 254 eyes with DR $(p=0.742){ }^{21}$. Possible factors that might have caused these contrasting results include different methodologies and definitions of refractive status. Secondly, the accumulation of water in the ocular lens and the amount of sorbital by-products alters the refractive indices of the eye in diabetics ${ }^{21}$. Thirdly, the stability of refractive status in diabetics is also determined largely through the stability of the serum glucose. Fluctuation of less than $80-100 \mathrm{mg} / \mathrm{dl}$ for the serum glucose levels over a three to four week period is recommended for stabilization of refractive error ${ }^{22}$. Other temporal factors include systemic and visual risk factors of DR and/or DME, changes in the tear layer; and increased cornea rigidity of diabetics, all which may also have indirect influences on autorefractor measurements.

Further investigation remains necessary to more completely understand the many complicated factors contributing to both short- and long-term variation in autorefraction in individuals with DM, and DR or DME. For example, a longitudinal study of several diabetic subjects with autorefraction at regular intervals would assist in further understanding the short-and long-term influences of DM, DR and/or DME on refractive state. However, hopefully this preliminary work provides some information in this regard and might provoke further studies in this field.

\section{Acknowledgements}

We thank Doctor VB Holland, staff, and the patients of Helen Joseph Hospital in Johannesburg, and Doctors Imraan R Munshi and Shashikant Kassen for their contributions towards diagnosing the fundus photographs.

\section{References}

1. Ziskind A. Diabetes and the eye. S Afri J Cont Med Edu 1998 16 513-517.

2. Kalk WJ, Pick WM, Sayed AR. Diabetes mortality in South Africa. S Afr Med J 199888 1259-1262.

3. Levitt NS, Bradshaw D, Zwarenstein MF, Bawa AA, Maphumolo S. Audit of public sector diabetes care in Cape Town, South Africa: high prevalence of complications, uncontrolled hyperglycaemia and hypertension. Diabetic Med 199714 1073-1077.

4. Rotchford AP, Rotchford KM. Diabetes in rural South Africa- an assessment of care and complications. SAMJ 2002 92 536-541.

5. Carmichael T, Carp GI, Welsh ND, Kalk WJ. Effective and accurate screening for diabetic retinopathy using a $60^{\circ}$ mydriatic fundus camera. SAMJ 200595 57-61.

6. Porta M, Allione A. Current approaches and perspectives in the medical treatment of diabetic retinopathy. Pharmacol Ther 2004103 167-177.

7. Gardner TW, Antonetti DA, Barber AJ, LaNoue KF, Levison SW and the Penn State Retina Research Group. Diabetic retinopathy: more than meets the eye. Surv Ophthalmol 200247 S253-262.

8. Ciulla TA, Amador AG, Zinman B. Diabetic retinopathy and diabetic macular edema: Pathophysiology screening and novel therapies. Diabetes Care 200326 2653-2668.

9. McKay R, McCarty CA, Taylor HR. Diabetic retinopathy in Victoria, Austrialia: the Visual Impairment Project. $\mathrm{Br}$ J Ophthalmol 200084 865-870.

10. Lee KE, Klein BE, Klein R, Wong TY. Changes in refraction over 10-years in an adult population: The Beaver Dam Eye Study. Invest Ophthalmol Vis Sci 200243 2566-2571.

11. Rubin A, de Klerk A, Marais K, van Rooyen B, Swanepoel D. Diurnal variation of autorefraction in a diabetic versus a non-diabetic subject. S Afr Optom 200463 65-76.

12. Harris WF. Algebra of sphero-cylinders and refractive error, and their means, variance and standard deviations. $A m$ J Optom Physiol Opt 198065 794-802.

13. Harris WF. Direct, vec and other squares, and sample variance-covariance of dioptric power. Ophthalmic Physiol Opt $19901072-79$.

14. Harris WF. Representation of dioptric power in Euclidean 3-space. Ophthalmic Physiol Opt 199111 130-136.

15. Harris WF. Signs of surface torsion and torsional dioptric power. Optom Vis Sci 199875 670-673.

16. Harris WF. Astigmatism. Ophthalmic Physiol Opt 200020 11-30.

17. Rubin A. Statistical analysis of autorefractor measurements on a single subject. S Afr Optom 1993 52 91-97. 
18. Gillan WDH, Harris WF. Dark refraction shift: a comparison of prepresbyopes and presbyopes. S Afr Optom 2004 63 42-46.

19. Willkinson CP, Ferris FL, Klein RE, Lee PP, Agardh CD, Davis M, Dills D, Kampik A, and the Global Diabetic Retinopathy Project Group. Proposed International Clinical Diabetic Retinopathy and Diabetic Macular Edema Disease Severity Scales. Ophthalmol 2003110 1677-1682.

20. Sukha AY. Demographic, medical, and visual aspects of diabetic retinopathy and diabetic macular edema. Magister Philosophiae, Department of Optometry, University of Johannesburg, Johannesburg, South Africa, 2007.

21. Espiritu RB, Sy GT. Fluorescein angiographyically evident in diabetic maculopathy. Clin Hemorheol Microcircul 200329 357-365.

22. Blaustein BH. Ocular Manifestations of Systemic Diseases. New York: Churchill Livingston Inc, 1994. 